\title{
Conception and Implementation of Geographical Database for Cultural Heritage Management-Case of Historical Jeddah, KSA
}

\author{
Atef Belhaj Ali ${ }^{(0,}$, Abdulmohseen Al Shareef, Oussamma Jastania \\ Department of Geography and GIS, Faculty of Arts and Humanities, King Abdul Aziz University, Jeddah, KSA \\ Email: amalhabeb@kau.edu.sa
}

How to cite this paper: Belhaj Ali, A., Al Shareef, A. and Jastania, O. (2021) Conception and Implementation of Geographical Database for Cultural Heritage Management-Case of Historical Jeddah, KSA. Journal of Geographic Information System, 13, 696-709.

https://doi.org/10.4236/jgis.2021.136038

Received: September 15, 2021

Accepted: December 20, 2021

Published: December 23, 2021

Copyright $\odot 2021$ by author(s) and Scientific Research Publishing Inc. This work is licensed under the Creative Commons Attribution International License (CC BY 4.0).

http://creativecommons.org/licenses/by/4.0/ (c) (i) Open Access

\begin{abstract}
Saudi Arabia is attempting to develop a long-term tourism business that respects Islamic ideals, heritage, and traditions. In accordance with the "Vision of the Kingdom of Saudi Arabia 2030", significant emphasis has been placed on developing and promoting cultural tourism as a result of the Kingdom's very valuable civilizational and cultural heritage, in addition to entertainment and improving the quality of life. The city of Jeddah in the Kingdom of Saudi Arabia's second capital, and the district known as "Al-Balad", which is located in the city's core, is a historical neighborhood known for its old structures and multi-story houses. Since 1947, the historical monuments in the Al-Balad region have faced major and challenging issues as a result of neglect and a failure to maintain them. To protect this historical architectural heritage, the United Nations Educational, Scientific, and Cultural Organization (UNESCO) has designated Jeddah's historic area as a World Heritage Site. The purpose of this research is to identify historical sites in the city of Al-Balad using existing maps, field surveys, and the design and creation of a spatial database that can be used with geographic information systems (GIS). By combining the results of the spatial database and photographic surveys with the history of Old Jeddah, an application was created and made available to users and those interested in the Internet that can be used through mobile devices (mobile phones and tablets) to introduce the historical area of Jeddah and promote tourism in Old Jeddah.
\end{abstract}

\section{Keywords}

Geographic Database, GIS, Historical Jeddah, Cultural Tourism

\section{Introduction}

Tourism's development and emergence as an important industry with economic 
and social benefits, together with other resources and services, contribute to a country's economic prosperity. In terms of human and natural factors that come from a variety of different sources, the tourism industry represents a complex and intertwined process that requires coordination and modeling in the form of databases and maps to help dispose of information and make tourism planning processes more effective.

Planning activities require a massive amount of accurate and thorough information with a spatial dimension, as well as the use of effective scientific tools such as geographic information systems and geographic databases, which enable easy and quick recall and query on data. It is also a vital instrument for storing geographical information and its nature, as well as monitoring all resources and developing models that aid in simulation and decision-making in the sphere of tourism development. On the other hand, with recent advancements in web-based GIS applications, the process of data access, sharing, dissemination, and analysis has changed, as web-based GIS uses the internet to access and transfer data, as well as analysis tools to improve the visualization and integration of spatial data. Users can also access a large range of multimedia data that is completely integrated on the Web through the multimedia geographic information system. GIS and multimedia also give users tools for analyzing and visualizing spatial data as well as linked multimedia material on the Internet.

This study aims to create a geographical database on the historical area of Jeddah to aid in the management and planning of archaeological sites, with an attempt to comprehensively document all sites and to develop and operate a GIS application on the Internet for the study area. Data obtained from various sources were collected using GIS software, a GIS application developed, and a website configured to serve the system on the Internet. The integration of spatial data with multimedia information simplifies the inventory, evaluation, and upkeep of historical sites. The many forms of information gathered through this study can be transmitted to end users with modest technological requirements.

This study emphasizes the significance of this study in the use of GIS technology and its various applications in collecting, documenting, and managing archaeological sites within a database characterized by durability and sustainability, on the one hand, and designing and developing a GIS application that can be made available to users of archaeological sites in the historical Jeddah region, on the other.

\section{Study Area}

Jeddah is located in western Saudi Arabia, on the Red Sea's eastern coast. It is one of the twelve provinces that comprise the Makkah Al-Mukarramah province. The city was founded around $350 \mathrm{BC}$ by a group of fisherman [1] and is now regarded as the second largest city in the Kingdom of Saudi Arabia in terms of population after Riyadh. The city has a population of approximately 3.9 million people. It is one of the most prominent cities on the Red Sea coast in the Kingdom of Saudi Arabia. Jeddah is an important city in the Kingdom of Saudi 
Arabia because it possesses the most important Red Sea seaport [2], which has aided its development throughout history, as well as a vital commercial center at the local and regional levels. Jeddah is now Saudi Arabia's business capital. It is also quite important in Mecca, particularly in the events linked with the Hajj and Umrah rituals.

Jeddah has an area of about 1320 square kilometers. It is administratively divided into 66 districts, which are separated into four groups: north of Jeddah (17 districts), central Jeddah (22 districts), south of Jeddah (23 districts), and eastern neighborhoods and eastern neighborhoods of Jeddah (4 districts) [3]. Jeddah's historic area is the city's beating heart, from which business, development, and urban trends began and extended, particularly in the twentieth century, to the north, south, and east. Historic Jeddah is located within what is currently known as Al-Balad District, one of Jeddah's core districts. The historic core is around one square kilometer and has a population of approximately twenty-five thousand people. This center region is dominated by commercial and residential uses.

The government of the Custodian of the Two Holy Mosques, through the General Authority for Tourism and Antiquities, has taken the initiative to nominate the Historic District of Jeddah for inclusion on the list of the United Nations Educational, Scientific, and Cultural Organization (UNESCO) [2]. The inclusion of the Jeddah Historic District on the list of the United Nations Educational, Scientific, and Cultural Organization is contingent on the historical, architectural, and urban values of this site at the local and regional levels, as it is regarded as the most important architectural site along the Red Sea shores in Asia and Africa. Jeddah's historical district contains a collection of historical structures with distinguished architectural design from various eras. This location was chosen because of its most important multicultural site, as well as its distinctive architectural structures showing important periods of human history, local culture, and customs with universal significance [4].

Although the historical and architectural values of the region's structures differ, the UNESCO World Heritage Committee treats all of these buildings on the basis of equal values and importance. The inclusion of this area on the World Heritage List will help to conserve the city of Jeddah in particular and the Kingdom of Saudi Arabia in general, as well as provide it with international tourist and heritage value. The map below (Figure 1) depicts the Al-Balad region as well as the boundaries of the historic Jeddah region.

\section{Methodology}

Geographical databases are described as a structured collection of data that can be accessed on a regular basis, making them an essential component of geographic information systems in which data is organized using various types of database management systems (DBMS: Data Base Management Systems) [6] [7]. On this premise, and in accordance with commonly known database development methods, the process of constructing a geographical database for 


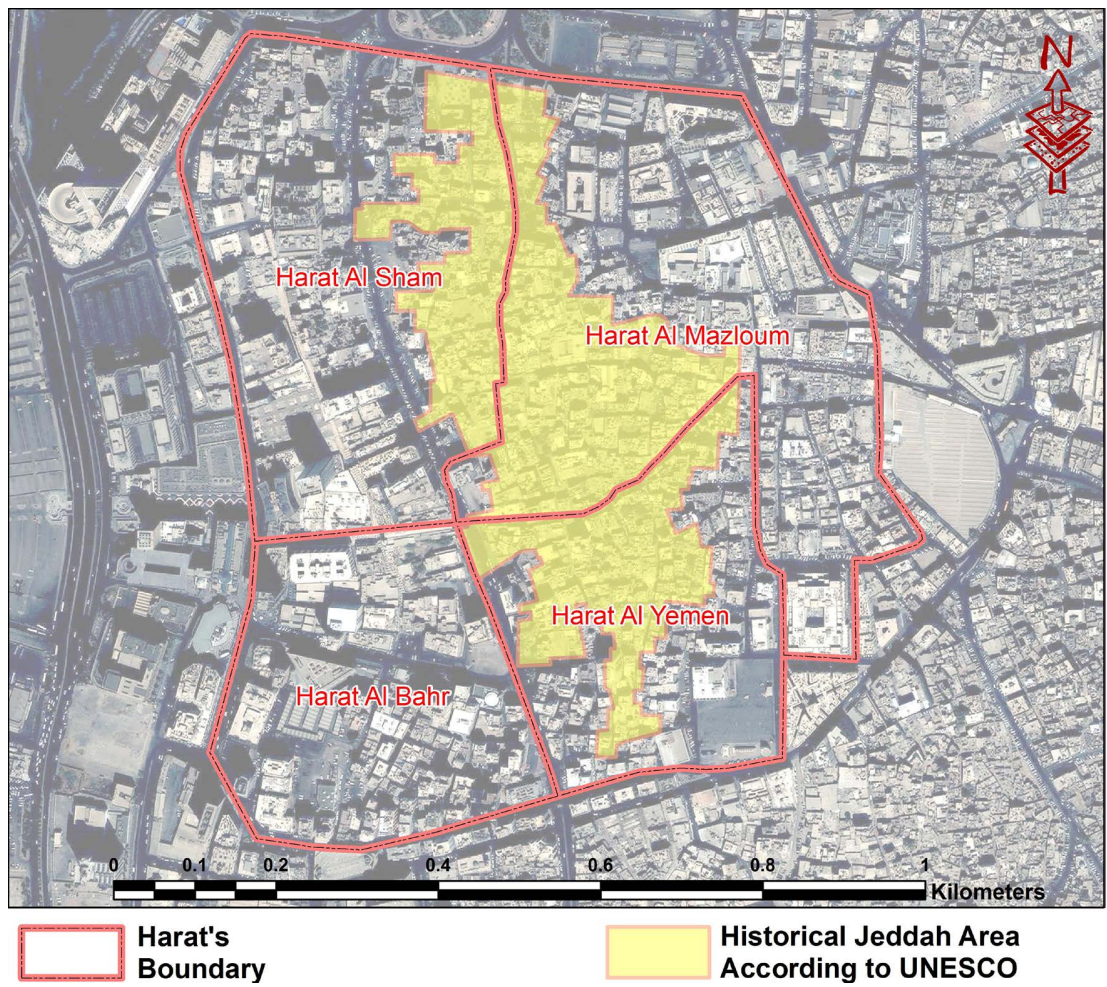

Figure 1. Study area (Historical Jeddah Area) (information source: [5]).

archaeological sites in the ancient Jeddah region went through the following technical and methodological stages.

\subsection{Needs Assessment}

To ensure the system's success, it is necessary to do an early analysis of the end user's needs and requirements. Current data or information, supporting data, hardware and software used, user background, level of experience, and other pertinent information will be determined at this time. Previous studies and research connected to the subject of the study [8] [9], as well as what the country wishes to grow cultural tourism within the 2030 vision, can be used to determine the challenges encountered as well as the aims and scope of the study. The list of documented buildings has been divided into categories based on the type of building, such as traditional residences or museums, religious structures, or monuments.

\subsection{Creation of the Database Conceptual Model}

Geographic data is a type of data that defines things based on their location. Geodata contains geographic information as well as meta information, which is information about the entity. The links between entities are described in data modeling, as well as a clear and succinct specification of the entities and their features. "The historical home is located in a Harat", for example, is an illustration of the interaction between a Harat and a historical house. One-to-one, one-to-many or many-to-many relationships are possible between entities. The 


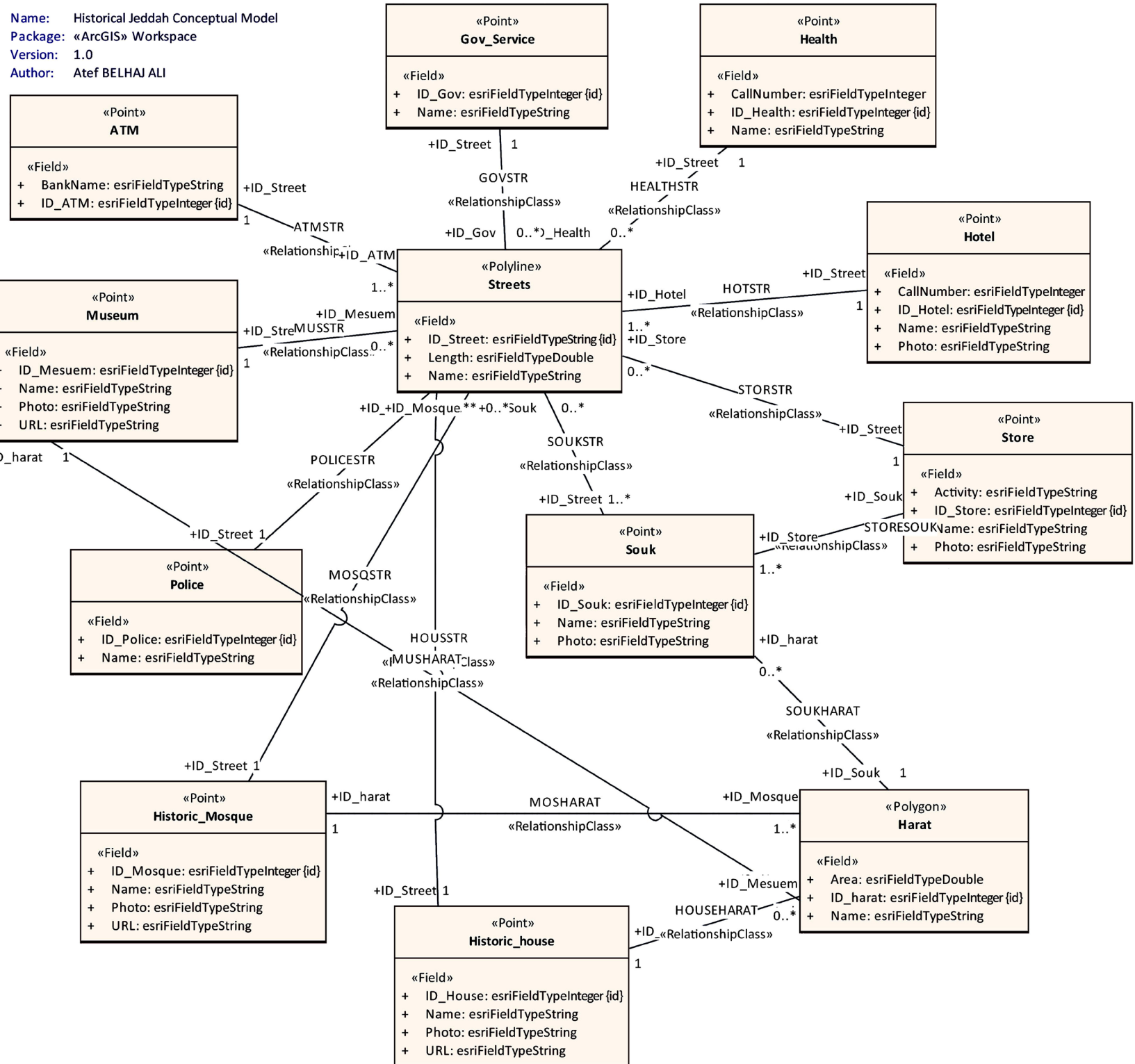

Figure 2. Conceptual model of historical Jeddah Geodatabase. 

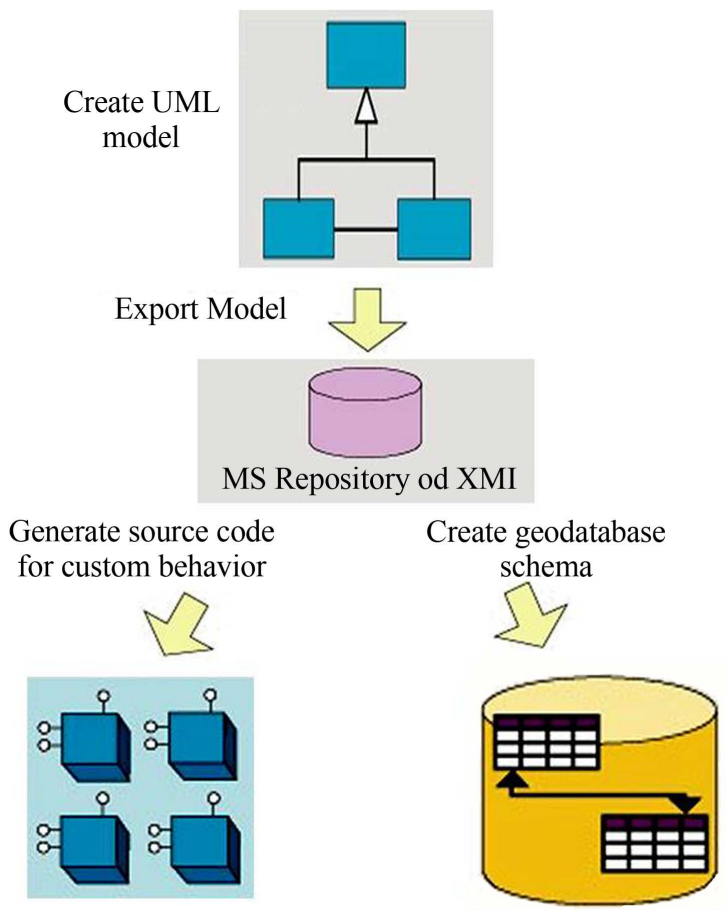

Figure 3. Design and development of a geodatabase using the UML CASE tool.

\subsection{Creation of the Database Logical Model}

A data model is a formal definition of the data that is needed in a GIS. A data model is a well-organized list and diagram of the relationships between entities. The goal of the data model and the modeling process is to ensure that data is identified and represented in a completely rigorous and unambiguous manner, and that both the user and the GIS analyst agree on the definitions of the data. The formal specification of entities, their features, and the interactions between entities for GIS is then referred to as a data model. The following table (Table 1) displays the entity data layers, types, and descriptors that were chosen for geodatabase construction in this study as a consequence of the user requirements analysis.

The following are the most important database entities, as listed in the previous table:

Street network: This entity contains the following descriptive information: ID, name, length and mainly represents the roads designated for pedestrians within the historic Jeddah area.

Al-Harat: This represents the division of the region into the so-called "Harat". The historical area is divided into four Harat: Haret Al-Sham, Haret Al-Mazloum, Hart Al-Bahr and Haret Al-Yaman.

Historic houses: They are the most prominent landmarks in Jeddah's historical district, adding to the region's cultural tourism identity. Despite considerable neglect and lack of care, these residences belong to the early inhabitants of Jeddah and are considered architectural marvels of exceptional beauty. Figure 4 shows on of these historical houses. 


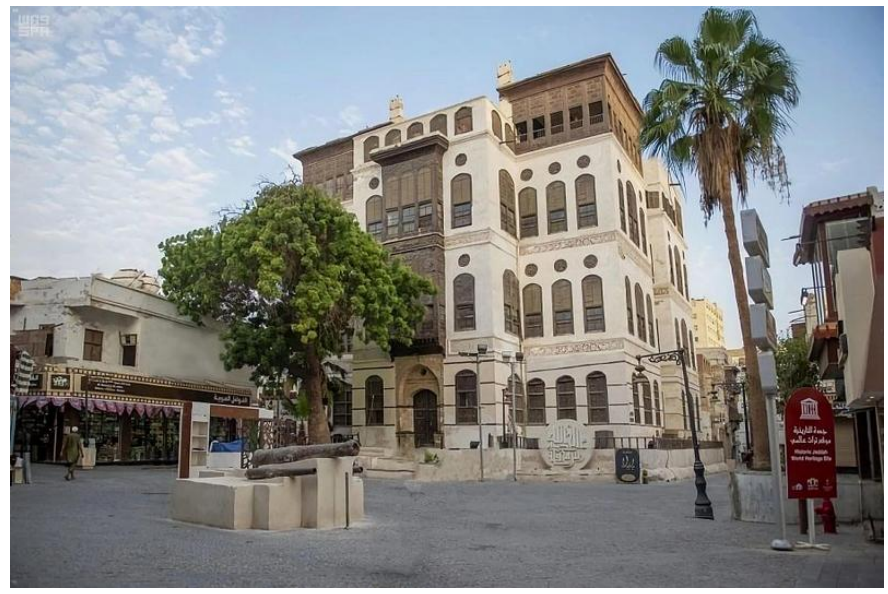

Figure 4. One of the historical houses called "Beit Nassif-Nassif's House".

Table 1. Data layers and their geometric and descriptive properties.

\begin{tabular}{|c|c|c|c|}
\hline Data & Layer & Type of feature & Attributes \\
\hline \multirow{3}{*}{$\begin{array}{l}\text { Historic } \\
\text { buildings }\end{array}$} & Historic houses & Point & $\begin{array}{l}\text { ID_House, Name, } \\
\text { Photo, URL }\end{array}$ \\
\hline & Historic Mosques & Point & $\begin{array}{l}\text { ID_Mosque, Name, } \\
\text { Photo, URL }\end{array}$ \\
\hline & Museum & Point & $\begin{array}{c}\text { ID_Museum, Name, } \\
\text { Pohto, URL }\end{array}$ \\
\hline \multirow{6}{*}{ Services } & Government Services & Point & ID_Gov, Name \\
\hline & Health Services & Point & $\begin{array}{l}\text { ID_Health, Name, } \\
\text { call_number }\end{array}$ \\
\hline & Hotels & Point & $\begin{array}{l}\text { ID_Hotel, Name, } \\
\text { Photo, call_number }\end{array}$ \\
\hline & Stores & Point & $\begin{array}{l}\text { ID_Store, Name, } \\
\text { Activity, Photo }\end{array}$ \\
\hline & Police & Point & ID_Hotel, Name \\
\hline & ATM & Point & ID_ATM, Bank_Name \\
\hline Streets Network & Streets & Line & ID_Street, Name, Length \\
\hline Harat & Harat & Polygon & ID_Harat, Name \\
\hline
\end{tabular}

Historical mosques: Based on the field survey that we conducted for this study, it appears that these landmarks are dispersed across the entire geographical area of the region, owing mostly to the city's citizens' dedication to their traditions and religious constants. Figure 5 shows on of these historical mosques.

Museums: The majority of them have lately been constructed inside historical buildings and residences, and they display antique images, as well as domestic equipment, demonstrating the way of life for the city's residents. The city's rulers' valuable historical possessions are also on show. Figure 6 shows one of these museums. 


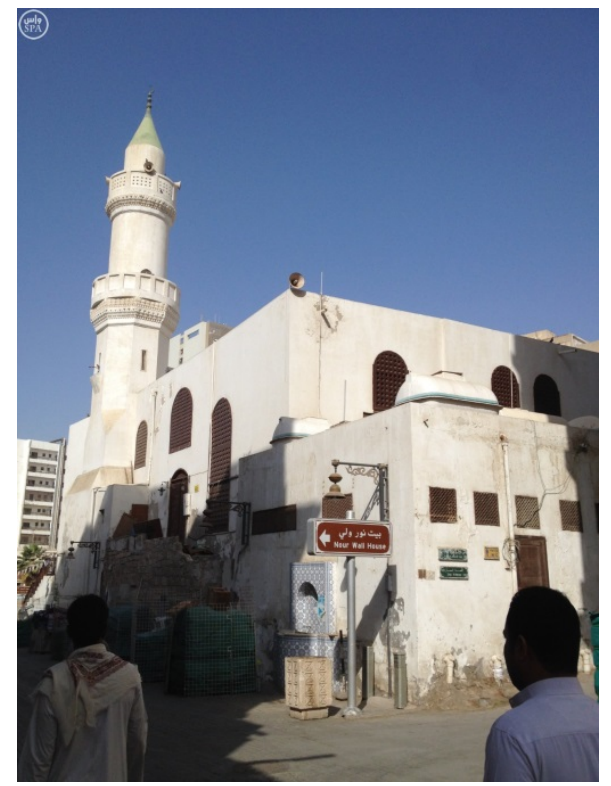

Figure 5. One of the historical Mosque called "Al Meemaar Mosque".

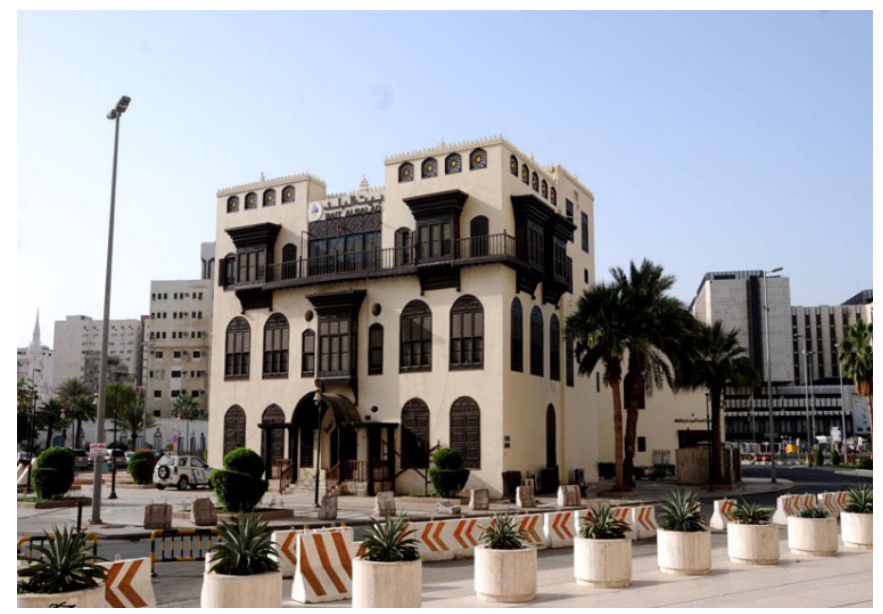

Figure 6. One of the Museums called "Beit Al Balad".

\subsection{Data Gathering and Database Physical Model Creation}

At this point, all of the data required to complete the geographical database had been obtained and rectified in accordance with what had previously been modeled. All spatial data relating to monuments, ancient sites, and modern sites that have a spatial dimension that can be calculated using the (X and $\mathrm{Y}$ ) coordinates were collected. The data is divided into three types of phenomena. When features are depicted on maps, they are represented as homogeneous layers with three fundamental geometric shapes: point, line, and polygon. For all levels included in the database, the Mercator WGS84 system is used. Using ArcGIS software, the database was produced in File Geodatabase format. The information was gathered from many sources and was mostly reflected in reference data from the Municipality of Jeddah, survey and field inspection using satellite imagery, and the usage of references and prior research. 
The following figure (Figure 7) represents the locations of the landmarks (dots in black) that were collected and preserved within the geographical database of the historical region of Jeddah.
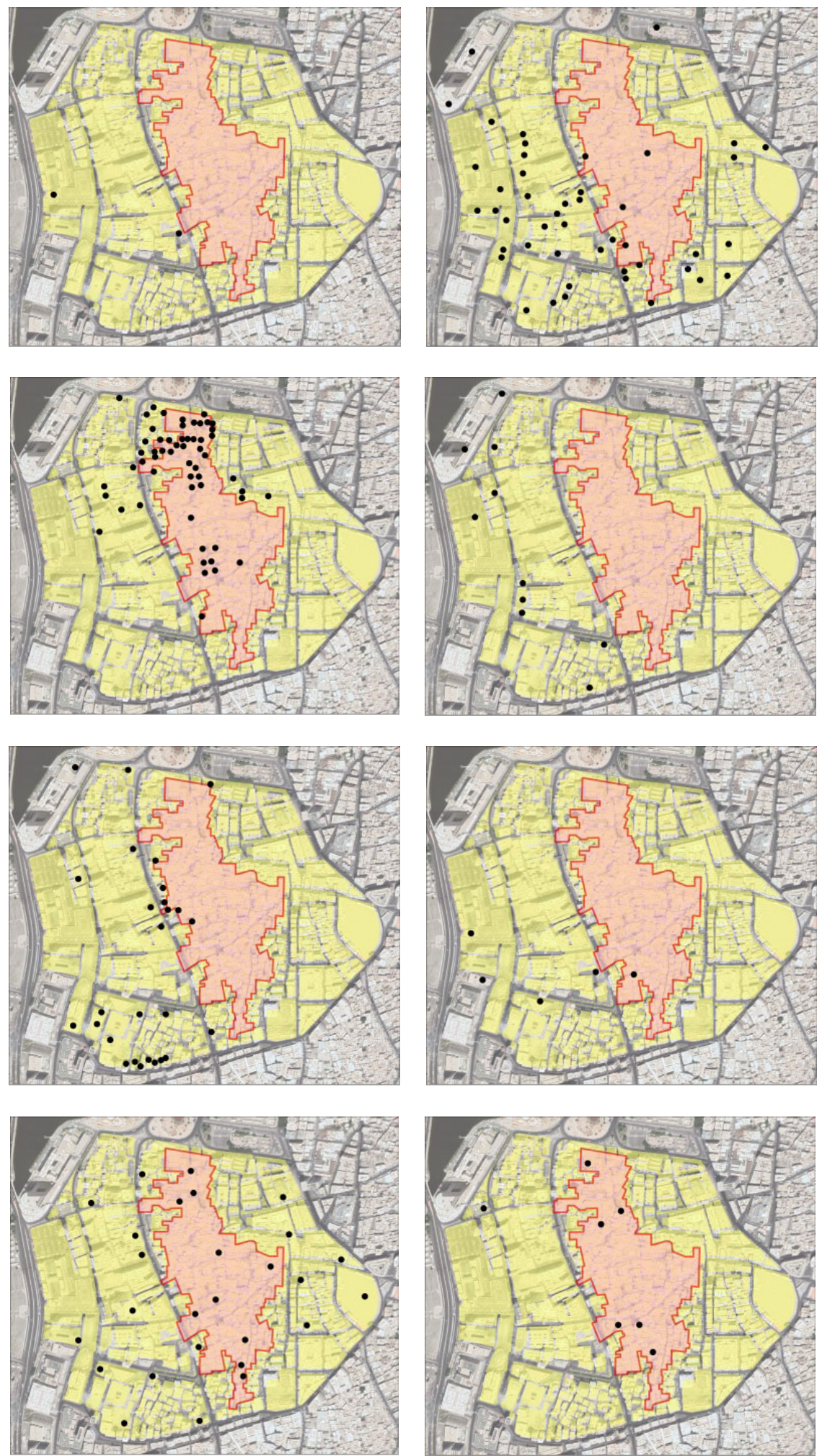

Figure 7. Locations of the landmarks. 


\section{Results}

This research resulted in the creation of a geographical database for the historical area of Jeddah, as well as the collection of all the data required to produce it. It was made with the ArcGIS application, which allows us to exploit the base at the level of searching for information, disposing of it, and updating it as needed. The graphic below depicts a query on the displayed map that allows the user to obtain the stored data and view the descriptive information for all of the stored entities (Figure 8).

The following Figure 9 also shows a query on the layer of historical houses and shows the use of multimedia data such as calling the Wikipedia page (in

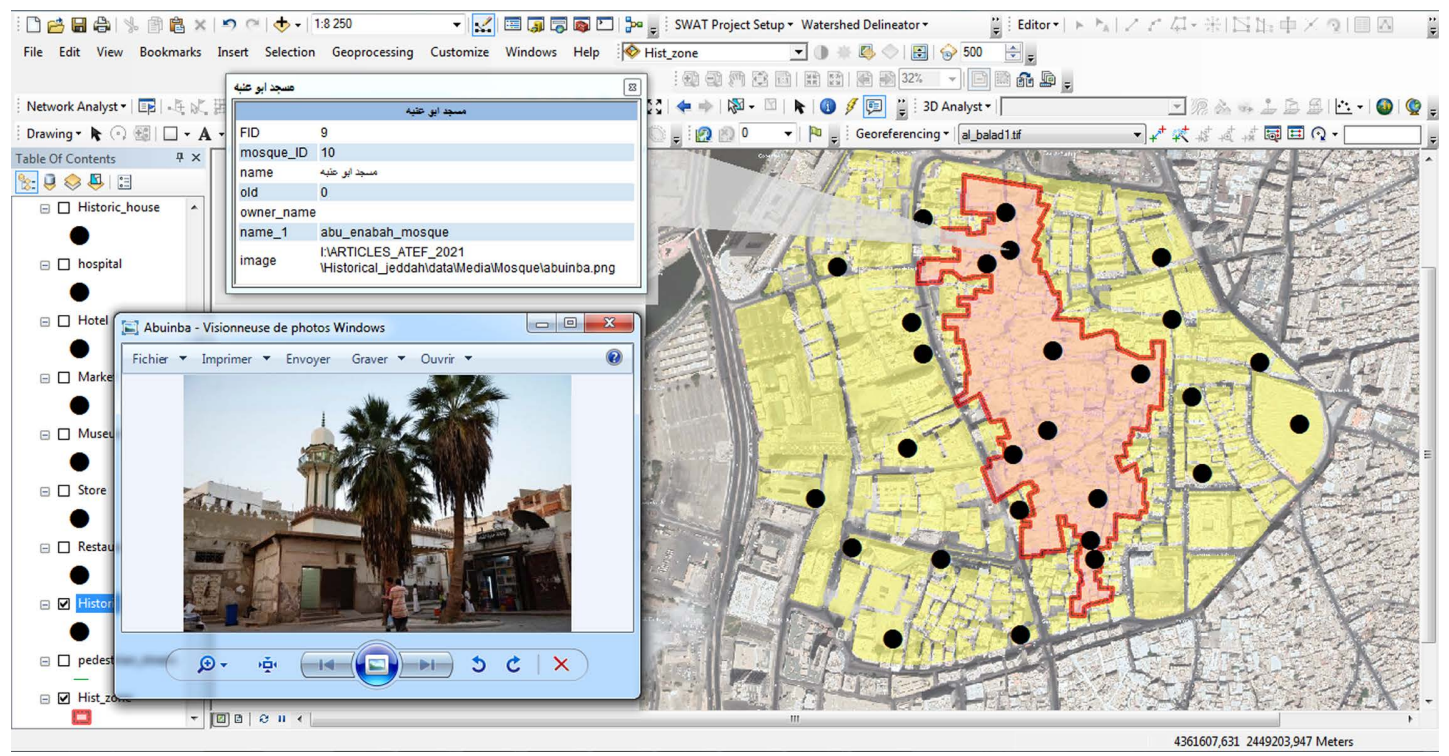

Figure 8. Example of query's result on the layer of ancient mosques.

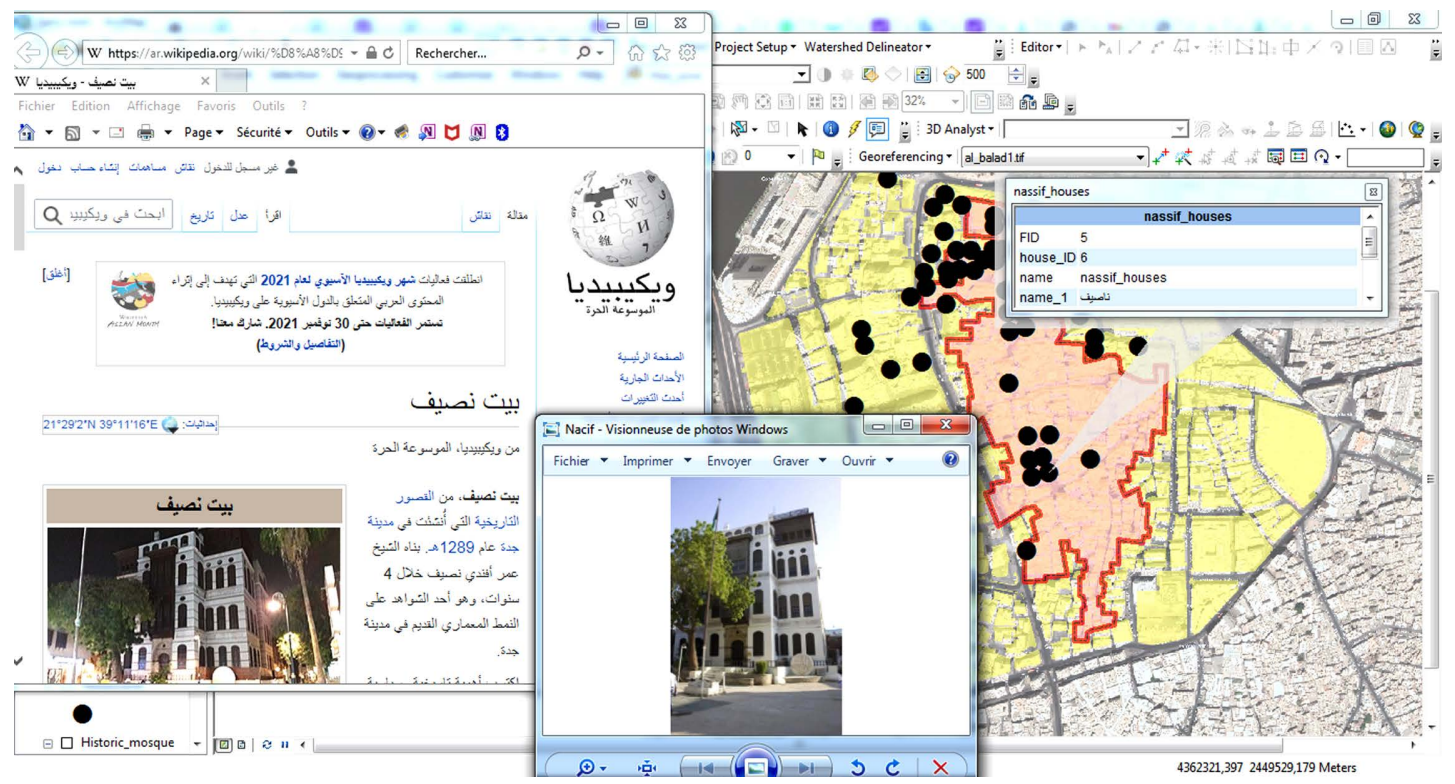

Figure 9. Example of query on the historical houses layer showing multimedia data. 
Arabic language) from the Internet describing the archaeological landmark "Nassif House".

\section{Design and Build an Application That Allows Online Viewing of the Data Stored in the Database}

The online and geo-portals applications are crucial for the promotion of any product, including tourism, and are a major source of exposing the region and enticing travelers to it; without them, we may miss out on a number of opportunities to promote tourism. Due to its simple accessibility in all regions of the world, the site can achieve various duties in the tourism development and promotion sector that no other approach can. What people want to know about tourism in a country can be gained by using an application or website that has all necessary information. According to [12], over $80 \%$ of travelers worldwide begin their tourism adventure on the Internet. As a result, in addition to the database that was established and created during this project, an online GIS application that allows users to access all of the recorded data was created.

Web GIS is a hybrid of the internet and a geographic information system. The web has eliminated distance limits in cyberspace, allowing non-professional people to connect with GIS applications worldwide and obtain information in real-time. Web GIS makes use of web technologies such as Hypertext Transfer Protocol (HTTP), Hypertext Markup Language (HTML), Uniform Resource Locator (URL), JavaScript, Web Graphics Library (WebGL), WebSocket, and others.

Web GIS, because it is based on the Internet and the Web has several benefits, according to [13], including:

- Easily exchange geographic information within your business and with people all over the world.

- It enables the distribution of completed programs to dozens or even millions of users using scalable cloud technologies.

- Lower cost: It is often less expensive to build a single Web GIS application than a traditional one.

- Better cross-platform capabilities: Web applications, particularly those built with JavaScript can run on computer and mobile browsers running a wide range of operating systems, including Windows, Mac OS, and Linux, as well as iOS, Android, and Windows Phone.

The ArcGIS Online platform was utilized to create the application and website. The database was transferred to the ArcGIS Online platform, and all settings and symbols for the features that would display on the map were defined. The metadata displayed to users was also determined by tampering with the pop-up settings for each data tier. Figure 10 depicts the platform during data loading.

Figure 11 represents a picture of the site available both on desktop and on mobile devises to all users to view the content of the database. 


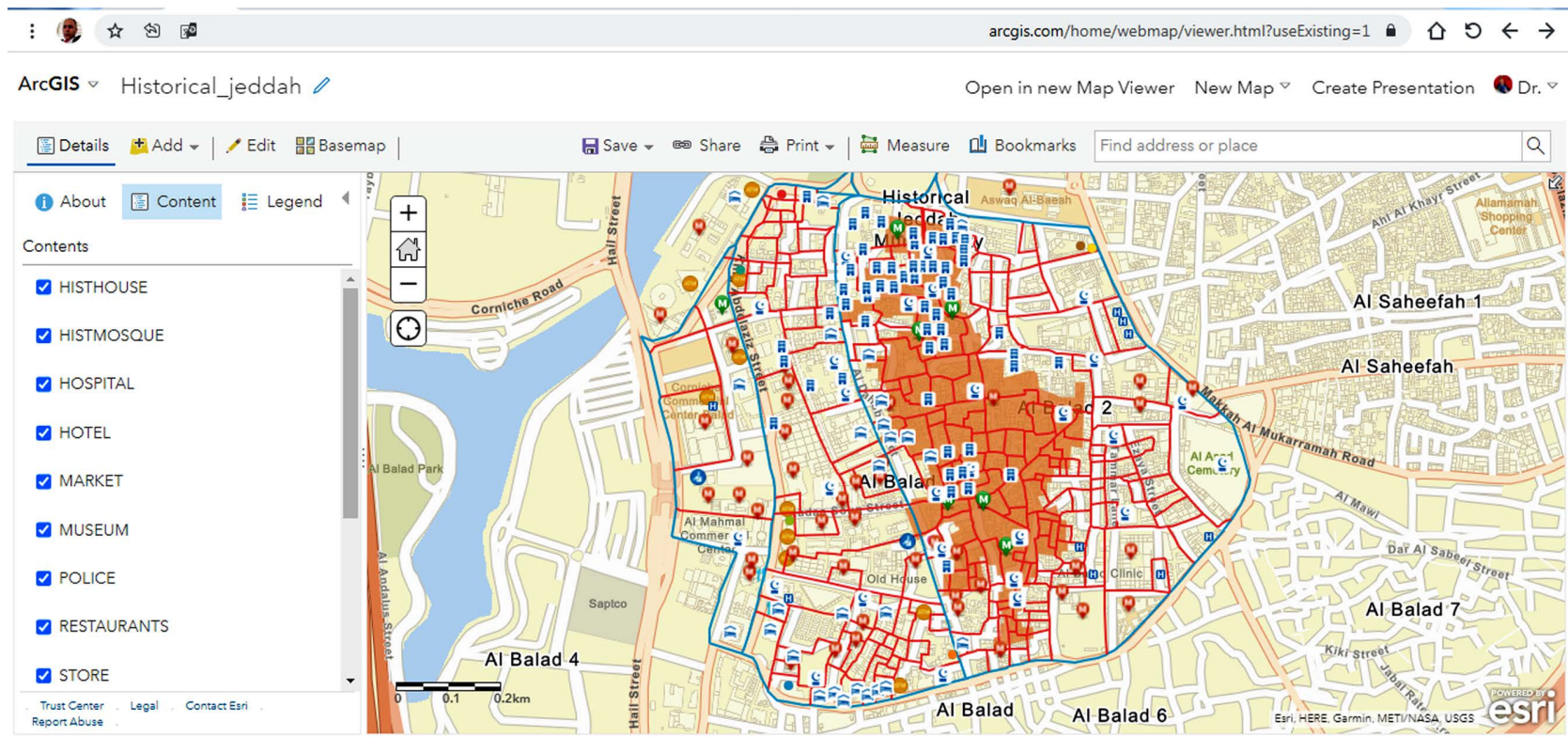

Figure 10. A printscreen of the ArcGIS online platform after the database has been loaded.

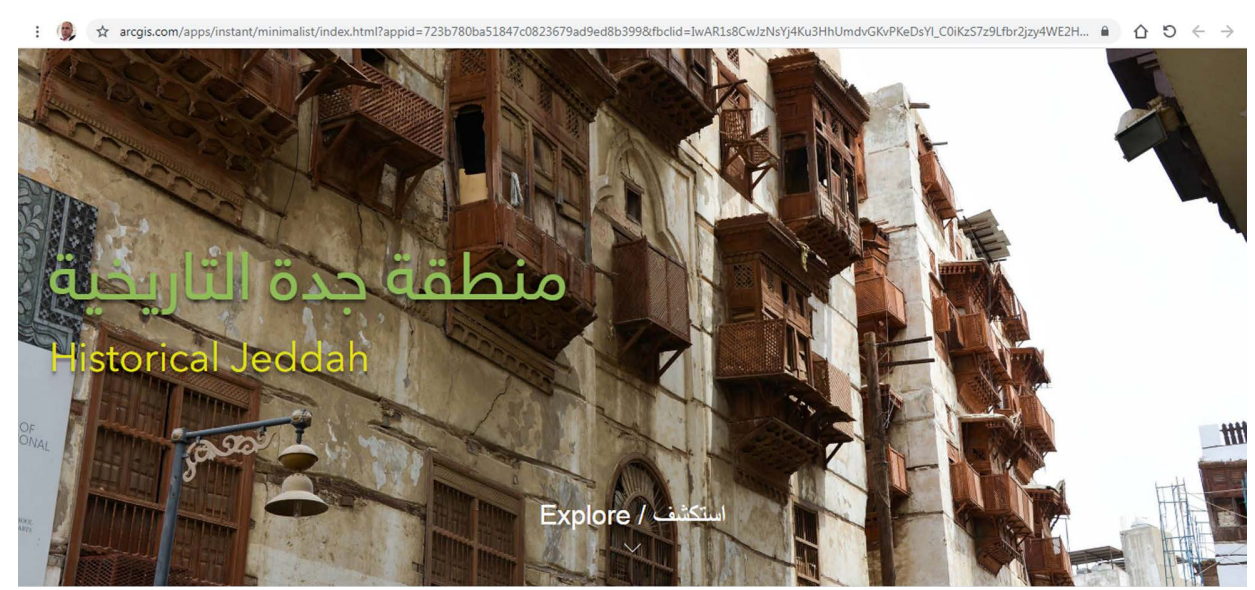

(a)

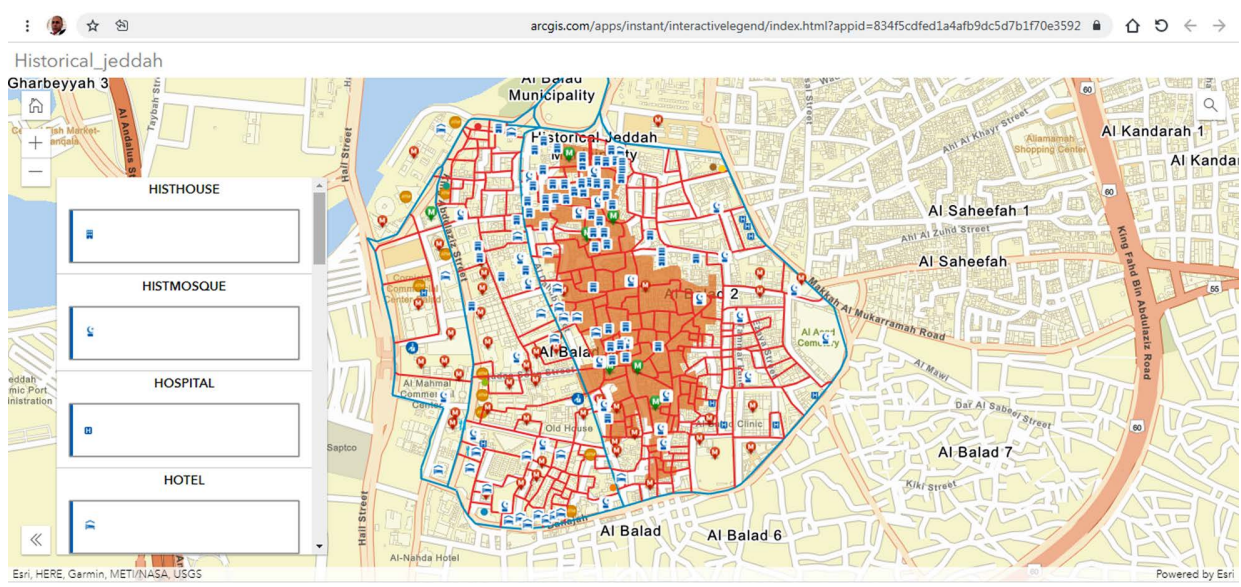

(c)

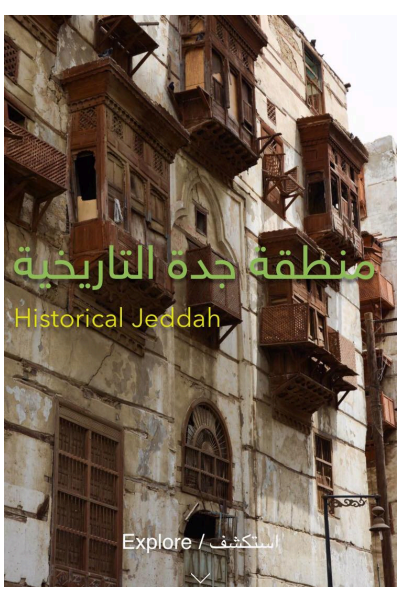

(b)

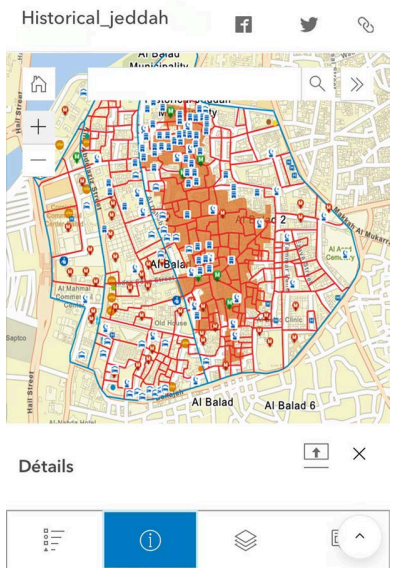

(d)

Figure 11. (a) Application frontpage on Desktop, (a) Application frontpage on Mobile devises, (c) Desltop application, (d) mobile Application. 


\section{Conclusions}

The Kingdom of Saudi Arabia's government is engaged in the tourist industry and its promotion. The government has made numerous initiatives in this area, most notably in the Kingdom's Vision 2030, which includes a series of targets aimed specifically at the entertainment and tourism industries. Jeddah's histori$\mathrm{cal}$ area is distinguished by its distinctive style buildings, traditional markets, historical mansions, historical mosques, and museums, all of which attract tourists. This study attempted to use the two best techniques in geographic information systems and the Internet (data access application) to enhance tourism in this key site. A geographic information system was utilized to catalog historical sites and map them. The maps also include descriptions of the locations so that travelers can readily comprehend and use them. A website has also been built that gives information on the locations of historical and historical monuments, as well as brief descriptions of those locations. This website will become a one-stop-shop for all information regarding historical sites in Historic Jeddah. This study demonstrated the significance of using geographic databases and geographic information systems to inventory archaeological sites, as we demonstrated that developing a geographic information system conceptual model is essentially a database design exercise that primarily includes formal modeling (preparing a data model) for a geographical database.

The design of the conceptual Scheme in the geographical database of heritage sites in the Historic District of Jeddah is an essential stage that must be implemented in the initial stage of constructing a GIS system. It starts with identifying the required data and progresses to a variety of different operations known as the data life cycle, which includes identifying data in a needs assessment, integrating data into the data model, producing metadata, and collecting and entering data. Data in the database update and maintain it, and lastly keep it and allowing for updates.

\section{Acknowledgements}

This project was funded by the Deanship of Scientific Research (DSR) at King Abdulaziz University, Jeddah, under grant No. G-537-125-1434. The authors, therefore, acknowledge with thanks DSR for technical and financial support. Dr. Atef Belhaj Ali, Principal Investigator.

\section{Conflicts of Interest}

The authors declare no conflicts of interest regarding the publication of this paper.

\section{References}

[1] Bagader, M. (2014) The Old City of Jeddah: From a Walled City to a Heritage Site. WIT Transactions on the Built Environment, 143, 365-374. https://doi.org/10.2495/DSHF140311 
[2] Azzam, A. and Belhaj Ali, A. (2019) Urban Sprawl in Wadi Goss Watershed (Jeddah City/Western Saudi Arabia) and Its Impact on Vulnerability and Flood Hazards. Journal of Geographic Information System, 11, 371-388. https://doi.org/10.4236/jgis.2019.113023

[3] Hamza, M., Thubaiti, A., Dhieb, M., Belhaj Ali, A., Garbouj, M. and Ajmi, M. (2016) Dasymetric Mapping as a Tool to Assess the Spatial Distribution of Population in Jeddah City (Kingdom of Saudi Arabia). Current Urban Studies, 4, 329-342. https://doi.org/10.4236/cus.2016.43022

[4] SCTA (2013) Heritage Sites in Saudi Arabia, a Special Report about the Heritage Sites that Registered and Nominated to Inscribe in the UNESCO WHC. Online Report on SCTA.com, Riyadh.

[5] Jeddah Municipality (2014) Historic Jeddah Building Regulations \& By-Laws. http://www.jeddah.gov.sa/english/

[6] Batini, C., Ceri, S. and Navathe, S.B. (1992) Conceptual Data Modeling: An EntityRelationship Approach. The Benjamin/Cummings Publishing Company, California.

[7] Chen, P. (1976) The Entity-Relationship Model: Toward a Unified View of Data. ACM Transactions on Database Systems, 1, 9-36.

https://doi.org/10.1145/320434.320440

[8] Elfadaly, A., Eldein, A.S. and Lasaponara, R. (2020) Cultural Heritage Management Using Remote Sensing Data and GIS Techniques around the Archaeological Area of Ancient Jeddah in Jeddah City, Saudi Arabia. Sustainability, 12, Article No. 240. https://doi.org/10.3390/su12010240

[9] Mahgoub, Y., Cavalagli, N., Versaci, A., Bougdah, H. and Serra-Permanyer, M. (2020) Cities Identity through Architecture and Arts. Advances in Science, Technology \& Innovation IEREK Interdisciplinary Series for Sustainable Development. Springer Eds. https://doi.org/10.1007/978-3-030-14869-0

[10] Bagui, S. and Earp, R. (2012) Database Design Using Entity-Relationship Diagrams. 2nd Edition, CRC Press Taylor and Francis Group, Boca Raton.

https://doi.org/10.1201/9781439861776

[11] Murphy, J. (2010). Using CASE tools in ArcGIS 10. ESRI. https://www.esri.com/arcgis-blog/products/arcgis-desktop/data-management/using -case-tools-in-arcgis-10/

[12] Sahahiri, R., Arrowsmith, C. and Alitany, A.A., et al. (2019) Mapping the Historical Places: A Case Study of Promoting Tourism in Jeddah, the Kingdom of Saudi Arabia. Cogent Arts \& Humanities, 6, Article No. 1691315. https://doi.org/10.1080/23311983.2019.1691315

[13] Fu, P. (2018) Getting to Know WebGIS. 3rd Edition, Esri Press. 